\title{
Etkin Bir Borç Yönetiminin Sağlanmasında Risk Yönetiminin Önemi
}

\author{
Haluk TANDIRCIOĞLU*
}

\begin{abstract}
$\ddot{O} Z$
Devletlerin ekonomide sorumlulukları arttıkça olağan kamu gelirlerinin yetersizliği nedeniyle borçlanmaya duyulan ihtiyaç da artmaktadır. Borçlanmanın artması borç yönetimini daha önemli hale getirmektedir. Günümüzde risk yönetimini içeren borç yönetimi vazgeçilmez bir mali ve ekonomik politika aracı olarak kullanılmaktadır. Borç yönetimleri sadece borçlanmak için değil optimal bir bileşimle borçlanmak için önlemler geliştirmektedir. Dolayısıyla borç yönetimlerine daha fazla iş düşmektedir. Borç yönetimleri, büyüklükleri ve etkileri birbirinden farklı risk türü ile karşılaşmaktadır. Özellikle gelişmekte olan ekonomiler için çok daha önem arz eden bu riskler kredi riski, borç çevirme riski, likidite riski piyasa riski, uzlaşma riski ve operasyonel risk olarak belirtilmektedir. Ayrıca piyasa riskinin ölçülmesi etkinliği sağlayıcı bir faktördür. Bu konuda senaryo analizi, risk altındaki değer analizi, risk altındaki maliyet analizi, dayanıklılık testi ve süre ve vadeye kalan ortalama süre analizi şeklinde teknikler kullanılmaktadır. Çalışmamızda öncelikle borç yönetimi ve risk yönetimi kavramları ve risk türleri ele alınmıştır. Risklerin, politika kararlarını etkilediği dikkate alındiğında risk türlerinin önemi daha fazla ortaya çıkmaktadır. Ardından risk ölçüm yönetimleri ve teknikleri incelenmiştir. Bu çerçevede aktif ve pasif borç yönetimi risk ölçümünde ayrıntılı bilgi veren tekniklerdir. Risk yönetimi teknik bilgiyi ve uygulama sonuçlarına ilişkin kontrolleri içeren etkin bir yönetimi ifade eder. Ancak gelişmekte olan ülkelerde bunun uygulamasında güçlükleri yaşanmaktadır. Bu güçlüklerin belirlenmesi önemlidir. Bu nedenle çalışmanın bir sonraki bölümünde risk yönetimindeki güçlükler incelenmiştir. Ardından Türkiye'de borç ve risk yönetiminin koordinasyonuna ilişkin düzenlemeler açıklanmıştır. Çalışmanın sonuç bölümünde ise borç yönetiminin önemi, bu süreçte yaşanan sorunlar ve bunlara karşı önlemler incelenmiş ve Türkiye'de borç yönetimine ilişkin sürecin genel bir değerlendirmesi yapılmıştır.
\end{abstract}

Anahtar Kelimeler: Borç Yönetimi, Risk Yönetimi, Risk Ölçüm Yöntemleri

JEL Sinıflandirması: H63, H68, G32

\section{The Importance of Risk Management In Establishing Effective Debt Management}

\begin{abstract}
As the roles of states increase, the need for borrowing increase due to insufficient public revenues. Due to the importance of borrowing, debt management becomes more important. Debt management (risk management) is used as a financial and economic policy tool. Another important issue is borrowing with an optimal composition. Debt management has more duties. There are several risk types which are important for developing countries such as rollover risk, liquidity risk, market risk, settlement risk, and operational risk. Measuring market risk is also important. Techniques such as senario analysis, value at risk, cost at risk, stress test and time analysis are used.In this paper, firstly, debt management, risk management, risk types are defined. Taking the effects of risks on political decisions into account, the importance of risk types become more relevant. Secondly, risk measurement techniques are analysed. Here, active and passive debt
\end{abstract}

*Dr. Öğretim Üyesi, Dokuz Eylül Üniversitesi İktisadi ve İdari Bilimler Fakültesi, Maliye Bölümü, haluk.tandirci@deu.edu.tr, ORCID Bilgisi: 0000-0003-4287-549X 
managemet are important techniques giving detailed information in risk measurement. Risk management includes technical information and control over implementation results. However, developing countries face serious problems in implementing risk management policies due to specific circumstances. That's why thirdly, the difficulties that the developing countries face in risk management are analysed. Forthly, the regulations in the coordination of debt management and risk management in Turkey are explained. In conclusion, the importance of debt management, the problems that occur in this process and the precautions that are taken against these problems are analysed and a general evaluation of Turkey's debt management is made.

Key Words: Debt Management, Risk Management, Risk Quantification Methods

JEL Classification:H63, H68, G32.

\section{GíRiş}

Kamu gelirleri arasında olağan dışı bir gelir kalemi olarak borçlanmanın önemi arttıkça borç yönetimi de otomatik olarak üzerinde daha fazla durulan bir konu haline gelmeye başlamıştır. Modern borç yönetimi uygulamaları borçlanmanın doğurduğu maliyetlerin minimizasyonunu sağlamanın ötesinde, borçlanma politikasının ekonomik ve mali hayatı yönlendirmede daha aktif kullanılmasına da neden olmaktadır. Borç yönetimleri artık risk yönetimini de içeren kompleks yapılara dönüşmüştür. Bütün dünyada görece önemi artan risk yönetimi ve risk ölçüm teknikleri, tüm güçlüklerine rağmen uygulanmaya çalışılmaktadır. Risk yönetimi uygulamaları ilk etapta borç idaresine ilave iş yükleri getirse de, daha sonra bu yükü ortadan kaldıracak faydaları sağladığı ve risk yönetiminin ihmal edilmemesi gerektiği artık kabul edilmiş durumdadır.

Gelişmekte olan ekonomiler arasında yer alan ve kamu borçlanmasına sıklıkla başvurduğu halde borç yönetimini yasal ve kurumsal zeminde modern anlamda yürütemeyen ülkemizde, 4749 sayılı Kamu Finansmanı ve Borç Yönetiminin Düzenlenmesi Hakkında Kanun sonrasında yeni bir döneme girilmiştir. Borç yönetimini sağlıklı şekilde yürütebilmek için yasal önlemler kurumsal tedbirlerle desteklenmiştir. Borç yönetiminde risk yönetimi konusuna da ayrı bir önem verilmeye başlanmıştır. Olası risklere karşı alınan tedbirler sayesinde hem borçlanma maliyetleri azalmış hem de borçlanma bir politika aracı olarak daha etkili bir şekilde kullanılmaya başlamıştır.

\section{I.BORÇ VE RISK YÖNETIMI KAVRAMLARI}

Borç yönetimi zaman içinde anlam genişlemesine uğrayan bir kavramdır. Önceleri sadece sözleşmeler çerçevesinde ele alınıp incelenen bir mahiyette iken zamanla ekonomi politikasını yönlendiren bir araç haline gelmeye başlamıştır. Esasen bu iki yaklaşım Kıta Avrupası Yaklaşımı ile Anglo-Amerikan Yaklaşım arasındaki temel farktan kaynaklanmaktadır.

Kıta Avrupası Yaklaşımı'nda borç yönetimi, sözleşme şartlarının belirlenen vadede borç sözleşmesinde yer alan hükümlerin borç süresince uygulanması ve lüzum gösterdiğinde gerçekleşen değişikliklere yönelik eylemleri içermektedir. Anglo-Amerikan Yaklaşımı'nda ise iktisadi amaçlara ulaşmak için borç yönetimi kullanılmaktadır (İnce, 2001:329).

Borç yönetiminin ana gayesi; makul bir risk seviyesinde kamu kesimi finansman gereksinimini ve ödemelerini minimum maliyetle karşılamaktır. Borç yönetimini aktif ve pasif borç yönetimi şeklinde ele alıp incelemek mümkündür. 
Pasif borç yönetimi, var olan verilere dayanarak borcun miktarına, ne zaman borçlanmaya gidileceğine ve hangi borçlanma araçlarının kullanılacağına ilişkin tespitleri içerirken; aktif borç yönetimi pasif yönetimin unsurlarına ilave olarak faiz ve kur riski gibi risk yönetim tekniklerini içermektedir (Dedeoğlu,1995:25).

Borç yönetimi çerçevesinde borcun miktarı ve bileşimindeki değişiklikler eğer ulaşılmak istenen ekonomik hedefler doğrultusunda gerçekleşiyor ise "arzulanan etkiler"; eğer sözleşmeden kaynaklanan hükümler sonucunda ekonomik hedeflerle uyumlu veya uyumlu olmayan değişiklikler doğuyorsa "önlenmesi mümkün olmayan” etkiler oluşmaktadır (Yaşa,1981:164).

Küreselleşme süreci ile birlikte ekonomiler birbirine daha bağımlı ve entegre hale gelmeye başlamıştır. Ekonomik hayat içerisinde önemli bir aktör olan devlet de bu sürecin dışında kalmamış ve küreselleşme sürecinden ve bu sürece bağlı iktisadi ve mali gelişmelerden etkilenmeye başlamıştır. Yeni ekonomik düzende artan risk ve belirsizlikler, borç ve risk yönetiminin önemini arttırmıştır. Borç yönetiminde etkinliği sağlamayan ülkeler mali ve ekonomik güçlüklerini neredeyse aşamaz hale gelmiştir. Geçmişte klasik metotların benimsendiği borç yönetimi başka bir forma dönüşmüştür. Bu dönüşümün pek çok sebebini sıralamak mümkündür. Ancak bunların en başında finansal piyasalarda yaşanan değişim ve bu piyasaların giderek daha büyük ölçekli hale gelmeye başlaması yer almaktadır. Sermaye hareketliliğinin en üst düzeyde görüldüğü bir dönemde bu sermayeye ulaşabilmek için kıyasıya bir rekabet yaşanmaktadır. Böyle bir ortamda ekonomi yönetimleri daha etkin olabilmek için sürekli reçeteler üretmeye çalışmaktadırlar. Kamu yönetiminde önceki dönemlerde bilinmeyen ya da bilinse de ihmal edilen performans konusu ön plana çıkmaya başlamıştır. Bu dönemde kur, faiz, menkul kıymet ve varlık fiyatları çok daha oynak "volatile" hale gelmiştir. Bu gelişmeler risklerin daha da artmasına neden olmuştur. Bu süreç swap, futures, forward, kuponsuz ve değişken faizli tahviller ve varlığa dayalı menkul kıymet gibi yeni araçların da ortaya çıkmasına neden olmuştur (Karacan,1997:21). Hem kamu kesimi hem de özel kesim tarafından son derece önemli etkiler doğuran bu süreç risk yönetimi uygulamalarını zorunlu hale getirmiştir.

Risk yönetimi öncelikle mevcut ve olası risklerin ne olduğunun ortaya konması, risklerin ölçümünün gerçekleştirilmesi, risklerin takip edilmesi ve risklerin denetim altına alınması adımlarından meydana gelmektedir (Pehlivan, 2003:388-389).

Borç yönetimi bu aşamaları gerçekleştirirken ülkenin mali ve ekonomik koşullarına göre belirlemeye çalıştıkları üst risk limitine göre hareket etmelidir. Yine borç portföyünün kendisinin de risk üzerinde etkisi olduğu unutulmamalıdır. Ancak kamu kesiminin borçlanmaya duyduğu ihtiyaç arttıkça bu riskler göz ardı edilebilmekte ve günü kurtarabilmek adına gelecek ipotek altına alınabilmektedir.

\section{RISSK TÜRLERI}

Borç yönetimleri, büyüklükleri ve etkileri ülkeden ülkeye değişen pek çok risk türü ile karşılaşmaktadır. Bu riskler, kredi riski, borç çevirme riski, likidite riski piyasa riski, uzlaşma riski ve operasyonel risk şeklinde sınıflandırılabilir. $\mathrm{Bu}$ 
risklerden özellikle piyasa ve borç çevirme riski finansal derinliği olmayan gelişmekte olan ekonomiler için daha çok önem arz etmektedir (Ateş, 2002: 17).

Tablo-1: Borç Yönetiminde Karşılaşılan Risk Türleri

\begin{tabular}{|c|c|}
\hline Piyasa Riski & $\begin{array}{l}\text { Hükümetin borç itfasını, faiz oranları, döviz kurları ve mal fiyatları üzerinde } \\
\text { gerçekleştirecekleri değişikliklerle bağlantılı riskleri ifade eder. }\end{array}$ \\
\hline $\begin{array}{l}\text { Borç Çevirme } \\
\text { Riski }\end{array}$ & $\begin{array}{l}\text { Borcun oldukça yüksek maliyetlerde çevrilmek zorunda kalınması veya çevrilememesi } \\
\text { riskidir. Bu riskin yönetimi özellikle gelişmekte olan piyasalara sahip olan ülkeler açısından } \\
\text { özel bir önem taşımaktadır. }\end{array}$ \\
\hline Likidite Riski & Borcun ödenmesinde kullanılacak likiditenin bulunamaması durumudur. \\
\hline Kredi Riski & $\begin{array}{l}\text { Borçlunun krediler ve diğer finansal kâğıtlar ile ilgili olarak karşı karşıya kaldığı performans } \\
\text { dışı risk veya finansal sözleşmelere imza atan bir tarafın bu sözleşmelerle ilgili aldığı risktir. }\end{array}$ \\
\hline Uzlaşma Riski & $\begin{array}{l}\text { Hükümetin bir taraf olarak veya farklı taraflar arasındaki uyuşmazlıkların çözümünde hataya } \\
\text { düşmesi durumunda karşı karşıya kalacağı riski ifade eder. }\end{array}$ \\
\hline $\begin{array}{l}\text { Operasyonel } \\
\text { Risk }\end{array}$ & $\begin{array}{l}\text { İşlemlerin kaydı ve yürütülmesi aşamalarındaki işlem hataları, dahili kontrol veya sistem ve } \\
\text { hizmetlerindeki yetersizlik veya hatalar, unvan riski, yasal risk, güvenlik ihaleleri veya ticari } \\
\text { faaliyeti engelleyecek doğal afetler gibi çeşitli risk türlerini içerir }\end{array}$ \\
\hline
\end{tabular}

Kaynak: Fred Jensen, Guidelines For Public Debt Management”, Proceedings of The Third Inter- Regional Debt Management Conference, Geneva, 3-6 December 2001, United Nations, Newyork and Geneva, 2003, UNCTAD / GDS / DMFAS / 3, p.125.

Borçlanma alanındaki riskler politika kararlarının alınmasını ciddi anlamda etkilemektedir. Bu riskler politika önlemleri arasında uyumu zorunlu kılmaktadır. Bu uyumlaştırmalara gidilirken borç ve rezerv yönetimi arasındaki uyum ilişkisinin ihmal edilmemesi gerekmektedir. Pek çok ülkede diş borç ve döviz rezervleri farklı birimler tarafindan yönetilmektedir. Bu durumun temel gerekçesi döviz rezervlerinin ve borcun farklı amaçlara göre yönetilmesi zorunluluğudur. Rezerv yöneticisinin temel çabası yeterli likiditeyi garanti altına almaya yöneliktir ve bu durum kısa vadeli ve oldukça likit varlıkların tutulması ile sonuçlanacaktır. Fakat borç yöneticisi tipik olarak refinansman risklerini sinırlandıracak uzun vadeli yükümlülükleri tercih edecektir. Bu iki farklı görevi iki farklı kuruma atfetmenin avantajı her kurumun belirlenen kriter çerçevesinde hesap verilebilirliğini sağlamasıdır. Rezerv ve borç yönetimi arasında koordinasyonun sağlanması, riske karşı korumasızlığı azaltmaktadır (Hawkins ve Turner, 2000: 26).

\section{PIYYASA RİSKİNIN ÖLÇÜM YÖNTEMLERI}

Borç yönetiminde karşılaşılan riskler içinde ölçülmesi ve önlem alınması gerekenlerin başında piyasa riski bulunmaktadır. Piyasa riskinin ölçülmesi için çeşitli teknikler kullanılmaktadır. Bunlar (Pehlivan, 2003:389-390);

1-Senaryo Analizi

2-Risk Altındaki Değer Analizi

3-Risk Altındaki Maliyet Analizi

4-Dayanıklılık Testi

5-Süre Analizi şeklinde sıralanabilir. 


\subsection{Senaryo Analizi}

Senaryo analizleri olası olayların gerçekleşme ihtimalinin ölçülmesini değil, olası olayların ortaya çıkması halinde portföyün nasıl etkileneceğini bulmaya çalışan bir analiz şeklidir. Bu senaryolar; tesadüfi kararlaştırılabilir, istatistiksel metotlarla geçmiş dataların analiz edilmesi yöntemiyle veya bir risk faktörünün farklı koşullarda nasıl davranacağına ilişkin çoklu tahminler kullanılarak oluşturulabilir (Türker, 2009: 4). Bu analiz yöntemindeki en büyük sakınca sürecin senaryolara ve süreci yönetenlerin sezgilerine ve birikimlerine bağlı olmasıdır. Senaryo oluşturmak, sonuçlarını değerlendirmek, değişik senaryoların birbiri üzerindeki etkilerini belirlemek ve olasılıkları sınırlandırmak temel güçlüklerini oluşturmaktadır (Uysal, 1999: 26).

Senaryo analizlerinde temelde tarihi senaryo analizi ve kurgusal senaryo analizi olmak üzere iki temel yöntem kullanılmaktadır. Örneğin tarihi yöntemde geçmişte yaşanmış bir krizin aynen tekrar etmesi durumunda oluşabilecek etkiler ölçülürken; kurgusal senaryo analizlerinde mevcut ekonomik koşullarla ve portföyün yapısıla uyumlu bir senaryo üretilerek, bu senaryo neticesinde oluşabilecek etkiler ölçülmektedir (Üzer, 2002: 22-23).

\subsection{Risk Altındaki Değer Analizi}

$\mathrm{Bu}$ analiz belli tahminler çerçevesinde, bir yatırım portföyünün değerinde oluşabilecek en yüksek zararları ölçmektedir. Risk altındaki değer analizi; olası portföy kayıplarını tek bir sayısal değer olarak ifade eden istatistiksel bir ölçüttür (Uçkun ve Kandemir, 2008:124).

Risk altındaki değer analizi, yaygın modellerden biridir. Çünkü basit ve anlaşılırdır. Model, değişik yatırım enstrümanlarının piyasa risklerinin ölçümünü ön plana çıkarması sebebiyle portföyün performansı katlanılan riske göre analiz edilmektedir. Bilhassa sermaye yeterliliğini belirlemek amaciyla bu modelin seçilmesi finansal kurumlar ve ülkeler bazında zorunlu tutulabilmiştir (Erçel, 1999:6).

Risk altındaki değer analizi portföydeki reel riski göstererek, riskin yoğunluklarını tespit etmekte ve portföy çeşitlendirilmesinin etkisini ortaya koymaktadır. Üstlenilen riske karşı eldeki sermayenin karşılaştırılmasını sağlayarak riske dayalı limitlerin belirlenmesine yardımcı olmaktadır (Yıldırım ve Çolaklayan, 2014:7).

Borç portföyün kısa bir vade içinde yeniden yapılandırılacağı haller için uygundur ve ağırlıklı olarak ikincil piyasalarda yoğun bir şekilde alım-satım yaparak ya da birincil piyasalarda geri alım, değişim ve takas ihaleleri yaparak borç portföylerinin yapısını değiştiren borç yöneticileri tarafindan kullanılmaktadır (Pehlivan, 2003:413). İkincil piyasalardaki işlemlerde hem cari riske maruz değer, hem de potansiyel riske maruz değeri hesaplanmaktadır.

Riske altındaki değer analizi risk ölçüm tekniği olmasının yanı sıra kamuoyuna bilgi verme aracı olarak kullanılabilmektedir. Bu teknik ilave olarak performans ölçüm standardı olarak da kullanılabilmektedir (Türker, 2009: 5). 


\subsection{Risk Altındaki Değer Analizi}

Risk altındaki maliyet analizi farklı makroekonomik senaryolar çerçevesinde alternatif borçlanma stratejilerinin olası maliyet ve risk değerlerinin hesaplanmasına imkân tanımaktadır (Kamu Borç Yönetimi Raporu, 2008: 39).

Risk altındaki maliyet analizi Danimarka Merkez Bankası tarafından geliştirilmiştir. $\mathrm{Bu}$ analiz çerçevesinde 2000 yılında farklı vadelerdeki dört ayrı borçlanma 2500 değişik senaryo altında on yıllık periyotta oluşturacağ 1 maliyetlerin olasılık dağılımını yapmış ve borçlanma maliyetleri ile sapma hesap etmiştir (Pehlivan, 2003:388-389).

Risk altındaki maliyet analiz ölçümü belirli olasılıklar aralığında borç servisinin maliyetini hesaplayarak artan faiz oranlarından kaynaklanan risk üzerinde yoğunlaşır. Faiz oranlarında gerçekleşebilecek olası değişikliklerle ilgili model ve varsayımlardan hareketle olasılıkların dağılımı hesaplanır (Mylonas, 2000: 14). Risk altındaki maliyet analizi ileriki dönemlerde faiz yükselmeleri nedeniyle oluşacak faiz yükünün bugünkü değerini hesap etmektedir (Ateş, 2002: 18).

\subsection{Dayanıklılık Testi}

Dayanıkl1lı (stres) testi küresel krizler döneminde ortaya çıan piyasalarda öngörülmeyen ve büyük ölçekli dalgalanmaların portföy değerlerini ne ölçüde etkilediğinin ölçümü için başvurulan bir yöntem olmaktadır. Test esasen, olağanüstü ekonomik koşularda portföyde doğan en yüksek değer kaybını ölçmeyi istemektedir. Hiç şüphesiz dayanıklılık testinin başarısı piyasa koşullarının doğru şekilde öngörülmesine bağlıdır (Erçel, 1999:7).

Mevcut stres testleri uygulanma amacına göre portföy düzeyinde stres testleri ve finansal sistem stres testleri şeklinde ikiye ayrılabilmektedir. Finansal kuruluşların kendi portföylerindeki kırılganlıkları portföy düzeyinde stres testleri; ilgili otoritelerce finansal sistemin kırılganlıkları finansal sistem stres testleri ile ölçümlenmektedir (Beşe,2007:4).

\subsection{Süre Analizi}

Süre, sabit getirili kıymetin faiz oranlarındaki değişimlere bağlı kaynaklanan fiyat dalgalanmasının bir ölçüsü olup farklı ölçüm yöntemleri söz konusu olmaktadır. Borç stokunun süre hesabında her bir senedin süresi bulunmakta ve borç portföyü içindeki ağırlık oranları belirlenmektedir. Faiz oranına karşı gösterilen duyarlılık borcun vadesine göre değişmektedir. Vade uzadıkça faizlerdeki değişime olan hassasiyet azalmaktadır. Uzun süreli borç stoku kısa süreli borç stokuna kıyasla faiz oranlarındaki değişime daha az duyarlı olmaktadır. Süre analizi borç portföyünün faiz oranlarındaki değişime olan duyarlılı̆gını ortaya koymakla beraber, nicelik boyutu hakkında bilgi vermemektedir (Pehlivan, 2003:412).

\section{IV.RISSK ÖLÇÜM YÖNTEMLERI}

Risk ölçüm yöntemlerinde, ilerleyen dönemlerdeki borç servisleriyle alakalı anapara ödeme takvimi, cari borçların faiz bileşimi, kamu kesimi borçlanma gereksinimi, ilerleyen dönemlerdeki faiz oranı ve kurlar gibi 
büyüklükleri dikkate alan "Yükümlülük Portföyü Yaklaşımı" ve fiyat iniş çıkışlarının sebep olduğu ekonominin riske maruz kalma oranlarını kontrol etmeyi hedefleyen "Aktif Pasif Yönetimi Yaklaşımı” incelenecektir..

\subsection{Yükümlülük Portföyü Yaklaşımı}

Yükümlülük portföyü yaklaşımında, ilerleyen dönemlerdeki borç servisleriyle alakalı anapara ödeme takvimi, cari borçların faiz bileşimi, kamu kesimi borçlanma gereksinimi, ilerleyen dönemlerdeki faiz oranı ve kurlar gibi büyüklükler dikkate alınmaktadır. Bu yaklaşımda öncelikle önceden belirlenmiş bir strateji ve piyasadaki fiyatlarla ilgili tahminlemelere dayanılarak, belirli bir zaman aralığında ve müdahale olmaksızın işleyen bir piyasa koşuluyla, ilerleyen dönemlerdeki muhtemel borç servis maliyetleri hesaplanmaya çalışılır. Daha sonra farklı varsayımlar çerçevesinde yeni öngörüler gerçekleştirilir. Bu öngörüler oluşturulurken istatistiki teknikler, tarihsel analizler, en kötü durum senaryosu gibi yöntemler kullanılır (Ateş, 2002: 28-29).

Yükümlülük portföy modelinin uygulanma amacı sadece riskten korunmayı sağlamak değil, aynı zamanda öz sermayeyi iyileştirmeye yönelik çeşitli imkanlar oluşturmaktır. Günümüz şartlarında finansal piyasalarda yaşanan rekabet koşulları dikkate alındığında, finansal aktörlerin sahip oldukları menkul kıymetlerin getirilerini risk faktörünü de dikkate alarak mümkün olduğu kadar arttırmak başlıca finansal aktör davranışı şeklinde karşımıza çıkmaktadır. $\mathrm{Bu}$ amacın gerçekleştirilmesi için menkul kıymetlerin bulunduğu portföyün etkin bir şekilde oluşturulması ve yönetilmesi gerekmektedir. Bu noktada portföy seçimi ve yönetimi optimal karar verilecek en önemli noktalardan biri olarak karşımıza çıkmaktadır (Uğurlu, Erdaş, Eroğlu, 2016:148).

Yükümlülük portföyü modeli devletin aktiflerini dışsal kabul ettiğinde, bazı sorunlarla karşı karşıya kalınmaktadır. Çünkü aktifler de pasifler gibi dışsal şoklardan etkilenmekte ve karşılaştıkları şokların yapısına göre kur ve faiz değişimlerine karşı duyarlılıkları değişebilmektedir (Ateş, 2002: 30). Bu nedenle aktiflerin yükümlülükleri karşılama oranına da bakmak gerekir. İlave olarak, bu kalemlerin dışsal olarak algılanması bunların finansal özelliklerinin hesaba katılmasında zorluklar çıkarır. Ayrıca aktifler, finansal şoklardan pasifler kadar etkilenmekle kalmazlar ve bunların kar veya faizlerdeki değişikliğe gösterdikleri duyarlılık şokun özelliğine göre çeşitlilik gösterir (Velendia:2004,19-20).

\subsection{Aktif Pasif Yönetimi (APY) Yaklaşımı}

$\mathrm{Bu}$ yaklaşım fiyat iniş çıkışlarının sebep olduğu ekonominin riske maruz kalma oranlarını kontrol etmeyi hedeflemektedir. Bu yaklaşım bir ülkeye ya da spesifik bir projeye ait varlık veya yükümlülük yapısında piyasalardaki dalgalanmalar sonucu, gelecekteki nakit akım yapısında oluşabilecek ters yönlü değişmeleri azaltmayı amaçlayan bir yaklaşımdır (Bal,2001:140).

Özellikle faiz oranı riski, finansal aktörlerin net faiz geliri ve dolayısıyla karlılığ1 üzerinde bir risk oluşturur. Faiz oranındaki değişiklikler (artış/azalışlar), finansal aktörlerin net faiz gelirini değiştirmekle kalmaz, bunun yanında öz sermayelerinin piyasa değerini de etkiler. Her iki durumda da finansal aktörler, bu riskin azaltılabilmesi için ellerindeki finansal varlıkların riske maruz kalma 
derecesini ölçmek ve bu riski azaltmaya ve ortadan kaldırmaya yönelik stratejilere oluşturmak durumundadırlar (An Oracle White Paper, http://www.oracle.com /us/industries/financial-services/045581.pdf).

Burada temel nokta, bir amaç fonksiyonunun belirlenmesi, bu amaç fonksiyonuna uygun olarak riske maruz kalma derecesinin veya duyarlılık seviyesinin belirlenmesi ve bunların ölçümünün yapılması, riske maruz kalma derecesine ilişkin kabul edilebilir bir seviyenin belirlenmesi ve riskten korunma yöntemlerinin seçimi ve bu yöntemlerinin uygulanmasına yönelik sürecin yönetilmesi büyük önem taşımaktadır (Bal, 2001:141).

Diğer yandan yükümlülük portföyü modelinin en önemli avantajlarından biri, bir finansal kurumun kaynakları ve fonları üzerinde etkin kontrol sağlayabilme yeteneğine sahip olmasıdır. Eğer finansal kurumların faize duyarlı varlıkları ve yükümlülükleri eşit ise varlıklardan sağladıkları faiz gelirleri ile yükümlülüklerinden kaynaklanan fonlama maliyetleri aynı oranda değişecektir (Structural Risk Management, www.dico.com. ).

Aktif pasif yaklaşımı; borç yöneticilerinin, vergi gelirleri ve borç portföyüne ilave olarak devletin diğer her çeşit varlık ve yükümlülüklerini bir bütün olarak dikkate almalarını sağlar (Ateş, 2002: 26). Bu yaklaşım kendi içinde ayrı ayrı aktif yaklaşım ve pasif yaklaşım olarak piyasa etkinliğini sağlama konusunda birbirinden farklı stratejiler içermektedir. Bu stratejilerden hangisinin uygulanacağı konusunda bazı sorulara cevap vermek piyasa etkinliğinin hangi yolla sağlanacağının belirlenmesi konusunda önem taşımaktadır.

Burada en önemli ve ilk sorulacak soru 'piyasaların etkin olup olmadığıdır'. Etkin kabul edilen piyasalarda finansal yatırımcıların pasif yönetim stratejisini kullanması, etkin kabul edilmeyen ama etkinliğin sağlanması amaçlanan piyasalarda aktif yönetim stratejisinin kullanılması önerilmektedir. Bir diğer soru, finansal yatırımın yurt içi ya da yabancı piyasa yapılıp yapılmadığıdır. Çünkü finansal piyasanın yönü de aktif ya da pasif yönetimin etkinliği açısından önemlidir. Nitekim, tüm finansal piyasalar eşit düzenlemelere tabi tutulmadığından gelişmiş piyasalar daha etkin iken gelişmekte olan piyasalar daha az etkindir (Fox, 2017:4).

$\mathrm{Bu}$ yöntemde kullanılan enstrümanlar Forwards, Futures, Options ve Swap anlaşmalarıdır. (Bal, 2001:143). Bu tür finansal türev ürünlerin rağbet görmesinin en önemli nedeni, türev piyasalardaki sözleşmelerle, yatırımcıların, kur, faiz oranı ve fiyat risklerine karşı korunma gereklilikleridir (Ceylan, 2004, www.finansbilimplatformu.com).

\section{V.RISK YÖNETIMIINDE KARŞILAŞILAN GÜÇLÜKLER}

Risk yönetimi, çok önemli düzeyde teknik bilgi, bu teknik bilginin edinilmesinde kullanılacak alt yapı, alınan kararların uygulanması ve sonuçlarına ilişkin kontrollerin gerçekleştiği bir yönetim şeklinde olmalıdır. Bu sebeple risk yönetimini gerçekleştirmek, gelişmekte olan ülkeler için çok daha zor olmaktadır. $\mathrm{Bu}$ ülkelerin günü kurtarmaya yönelik kısa vadeli politikalarının risk yönetimine dayalı bir şekilde tespit edilmesini beklemek aşırı iyimserlik olacaktır. Alınan politika önlemlerinde riskler göz önüne alınmak istense bile, aşağıda sıraladığımız 
bir takım sınırlayıcı unsurların bulunduğu gözden uzak tutulmamalıdır. Yine risk yönetimi tedbirlerinin kendisi zaman zaman sorunların bizatihi kaynağ1 olabilmektedir.

Risk yönetim birimleri / hazine yöneticileri açısından şu sınırlayıcı unsurlar önemlidir (Bal, 2001:171);

-Risk yönetimi, mevzuatın izin verdiği ölçüde gerçekleştirilebilmektedir.

-Ölçülemeyen riskler söz konusu olabilmektedir.

-Komisyonlar ve alış-satış farkları gibi gider kalemleri risk yönetimini güçleştirebilmektedir.

-Standart sözleşmeler nedeniyle korumasız kalan kısımlar olabilmektedir.

-Alınan pozisyonun üzerine yazılmış mevcut bir hedging enstrümanı bulunmayabilmektedir.

-Hazine ürünleri kredi riskini, yani bu ürünü satan tarafin yükümlülüğünü yerine getirmeme riskini tamamen yok etmemektedir.

-Finansman yöneticilerinin oluşturduğu beklentiler gerçekleşmeyebilmektedir.

Hükümetin borç yapısında bulunan riskler, yukarıda sayılan sınırlamalar da hesaba katılarak dikkatli bir şekilde izlenmeli ve değerlendirilmelidir. Bu riskler borç yapısını düzenleyerek ve bu düzenlemenin maliyetlerini hesaba katarak olabildiğince azaltılmalıdır.

Hareketli sermaye ve entegre sermaye piyasaları dünyası, hükümetlerin ellerinde tuttukları yabancı para cinsinden yükümlülükleri, bu ülkelerin her zaman yeterli derecede üstesinden gelemeyecekleri risklere maruz birakmaktadır. $\mathrm{Bu}$ ekonomilerin uluslararası sermaye piyasalarından kaynaklanan alışkanlıklara olan zaafiyetini azaltmaya yönelik olarak atılacak önemli bir adım, borç politikasını yönetmeye yönelik gerçekleştirilecek olan kurumsal düzenlemeler olacaktır. Böylece bu düzenlemeler; profesyonel, şeffaf ve kamusal manada hesap verebilir bir yapıyı teşvik edecektir (Cassard ve Folkters, 1997:38).

Arzulanan borç yapısı oluşturulurken, devlet nakit akışının mali ve diğer risk karakteristikleri göz önünde tutulmalıdır. Daha özelde ise, borç yöneticisi yabanc1 para birimi ve kısa vadeli veya değişken kurdan kaynaklanan riskleri dikkatlice değerlendirmeli, yönetmeli ve vadesi gelen borçların ödenmemesi riskinden kaçınmak için yeterince nakit olduğundan emin olmalıdır (IMF ve Worldbank, 2002: 34).

Bir devletin borç portföyü genellikle o ülkedeki en büyük finansal portföydür ve bu portföy genellikle karmaşık ve riskli finansal yapıları içerir ve devletin ödemeler dengesi bilançosu ile ülkenin finansal istikrarı için ciddi bir risk oluşturur (Storkey, 2001:7). Bu sebeplerle borç portföyünün büyüklüğü ve bileşimi ile ilgili kararları alan borç yönetimi idaresinin risk yönetimine özel bir önem vermesi gerekmektedir.

$\mathrm{Bu}$ nedenlerle günümüz kamu borç yönetimleri şeffaflığın artırılması, performansa dayalı etkin borçlanmanın minimum maliyet ve kabul edilebilir bir risk seviyesinde gerçekleştirilmesi için; maliyet ve risk hesaplamalarına bağlı olarak tespit edilen stratejik ölçüt (benchmark)* uygulamasına gitmektedir 
(Hazine Müsteşarlığı, 2004:62). Benchmarktan yalnızca borç ofisinin aktif borç yönetimi çerçevesinde ve müzakere süresince aldığı kararlar yoluyla vazgeçilebilir. Benchmark çerçevesindeki aktif borç yönetimi veya borcun yeni stratejik benchmarka uyumu, borcun vadesinde değişiklikler gerektirir. $\mathrm{Bu}$ faaliyet türevleri, tahvillerin geri alımını, tahvillerin değişimini veya yeni tahvil sürümünü gerektirir. İşlem maliyetlerini minimize etmek için borç yöneticisi aynı değişikliği vadesinde gerçekleştirmek için türev enstrümanlarını tercih edecektir. Swaplar, piyasa yapıcıları ile yapılan müzakereler sonucunda kolaylıkla gerçekleştirilebilir. Dahası açık arttırma usulü, kambiyo işlemleri ve geri alımlar çoğu zaman piyasaya olumsuz etkide bulunduğu halde swapların bu tür etkileri yoktur. Tüm bu sebeplerden dolayı iç borcunu aktif veya pasif bir şekilde yönetmek isteyen bir borç yönetimi birimi hedeflenen vadeyi tutturabilmek için türev araçlar kullanmayı tercih edebilmektedir (Piga, 2001:43).

\section{RISSK YÖNETIMI VE BORÇ OFISİ İLIŞKISİ}

Modern bir borç yönetimi sürdürülebilir bir borçlanma stratejisinin temelini oluşturmaktadır. Modern borç yönetiminin en önemli unsurlarından birisi ise risk yönetimidir. Borç yönetiminden sorumlu olan birimler risk yönetiminin aktif şekilde kullanılmasını sağlayacak şekilde borç yönetimlerini yeniden yapılandırmaktadır. Bu çerçevede uygulamalardan birisi de borç ofisleridir. Borç ofisleri borç yönetiminden sorumlu ve bir dereceye kadar özerk olan bir kurum olarak tanımlanabilecektir (Magnusson,1999: 2). Borç ofisleri ön, orta ve arka ofis şeklinde yapılandırılmaktadır.

Ön ofis, borçlanma süreci ile ilgili önceden onaylanmış borçlanma planına bağlı olarak en verimli fonlama maliyetine ulaşmaya çalışmaktadır (Worldbank, 2001: 51). Ön ofis borçlanılacak aracın türüne, vadesine ve yapısına karar vermektedir (Ateş, 2002: 10).

Ofis yapılandırması içerisinde en kritik görev orta ofise verilmiştir. Orta ofisin temel fonksiyonu, stratejik borç yönetimi ile risk gözetim ve kontrolü için gerekli analitik çalışmaları gerçekleştirmesidir (Worlbank, 2001: 60). Orta ofis portföy analizlerini üstlenmeli, borçlanma senaryoları geliştirmeli ve gerçekleşen borç göstergelerini önceden üzerinde uzlaşılan benchmarklarla kıyaslamalıdır (Kappagoda, 2004:7).

Arka ofisin temel görevi ise bir veri tabanının oluşturulmasını sağlamaktır. Arka ofis; genellikle borçların kaydedilmesinden, ödenmesinden, muhasebeleştirilmesinden ve güncelleştirilmesinden sorumludur (Akar, 2010, https://www.mevzuatdergisi.com/2010/04a/05.htm).

Borç ofisleri her ne kadar ön, orta ve arka ofis olarak sinıflandırılsa da; esasen bu üç ofis birbirleriyle koordineli olmalıdır

\section{TÜRKIYE' DE BORÇ VE RISK YÖNETIMININ} KOORDINASYONUNA İLIŞKİN ÇALIŞMALAR

Kamu kesimi finansman açıklarının çok doğru yönetilmediği dönemlerde ağır mali ve iktisadi faturalar ödemek zorunda kalan Türkiye, aynı sorunları tekrar yaşamamak ve sağlıklı bir borç yönetimine sahip olmak için pek çok yasal ve kurumsal önlem almıştır. Böylelikle borç yönetimi daha etkin, daha modern, daha 
şeffaf, risk yönetimini dikkate alan, borçlanma araçlarında çeşitliliği sağlayabilmiş ve borçlanma maliyetlerini olabildiğince minimize ederek finansal ihtiyacını karşılamaya çalışan bir yapıya sahip olabilmiştir. Türkiye'de borç yönetimi konusunda gerçekleştirilen en önemli yasal düzenleme 4749 sayılı Kamu Finansmanı ve Borç Yönetiminin Düzenlenmesi Hakkında Kanun'dur. Türkiye'de borç ve risk yönetiminin koordinasyonuna yönelik çalışmalar da bu kanun hükümlerine göre gerçekleşmektedir.

4749 Sayılı Kanunun birinci maddesine göre Kanunun amac1; "Ülkenin kalkınma hedeflerini dikkate alarak, piyasalarda güven ve istikrarı koruyarak ve makro ekonomik dengeleri gözeterek, Devletin iç ve dış borçlanmasına, hibe almasına, borç ve hibe vermesine, nakit yönetiminin maliye ve para politikaları ile koordineli bir şekilde yürütülmesine, verilecek garantilerin, bu borçlanma ve garantilerden doğan finansal alacaklar ile Devlet iç ve Devlet dış borcunun etkin bir şekilde yönetimine ve izlenmesine, Hazine Müsteşarlığı ${ }^{*}$ ile 2 nci Maddede yer alan kuruluşlar arasındaki malî ilişkilerin düzenlenmesine ve bu hususlar dahil olmak üzere Müsteşarlık tarafından üstlenilen her türlü malî yükümlülügüü geri ödenmesi, ilgili bütçe hesaplarına kaydedilmesi ve raporlanmasına ilişkin usul ve esasları düzenlemektir”. şeklinde düzenlenmiştir. Görüldüğü gibi Kanun, devletin borç yönetiminin sağlanmasını hedeflemektedir. $\mathrm{Bu}$ hedef doğrultusunda lafzından da anlaşılabileceği gibi;

Devletin iç ve dış borçlanması, hibe alması, borç ve hibe vermesi, nakit yönetimi, verilecek devlet ve hazine garantileri, borçlanma ve garantilerden doğan finansal alacaklarla ilgili temel çerçeveyi ortaya koymaktadır. Devlet iç ve Devlet dış borcunun etkin bir şekilde yönetimi Kanunun kapsamını belirlemektedir.

4749 say1lı Kanunun 16. Maddesine göre, "Bu Kanun kapsamında yer alan borçlanma ikraz ve garanti limiti, iç ve diş borçlanma, diş borcun devir, ikraz ve tahsisi, hibe alma ve verme, Hazine garantileri, garantisiz kamu borçlarına izin verilmesi, Hazine alacakları, diğer Hazine alacakları, nakit, borç ve risk yönetimi, risk hesabının işleyiş̧i, dış finansman temini izni verilmesi ve özel ihale usulleri ile sair konuların uygulanmasına yönelik esas ve usuller çıkarılacak yönetmeliklerle belirlenir." Hükmü yer almaktadır. 16.maddeden anlaşılacağ üzere risk yönetimi kamu borç yönetiminin temel unsurlarından birisini oluşturmaktadır. Kanunun düzenlemediği alanlar yönetmeliklere bırakılmaktadır.

4749 sayılı Kanunun verdiği bu yetki çerçevesinde 9 Mart 2019 tarihli Borç ve Risk Yönetiminin Koordinasyonu ve Yürütülmesine İlişkin Esas ve Usuller Hakkında Yönetmelik çıkartılmıştır. Adı geçen yönetmeliğin 5.maddesine göre "Borç, nakit ve risk yönetimi politikalarının belirlenmesi, gözden geçirilmesi ve uygulanması oluşturulacak komite* tarafından yerine getirilir. Komite üyeleri Bakan onayı ile belirlenir. Komite, aşağıdaki görevleri yürütür":

\footnotetext{
* Cumhurbaşkanlığı Hükümet Sistemine geçiş sonrasında yeniden yapılandırma sürecinde Hazine Müsteşarlığ1 Maliye Bakanlığı ile birleştirilmiş olup Hazine ve Maliye Bakanlığı olarak faaliyetlerine devam etmektedir.

* Borç ve Risk Yönetimi Komitesi
} 
a) ... yllda bir kez sonraki yll ile bu yll takip eden iki yll boyunca geçerli olacak borç, nakit ve risk yönetiminde esas alinacak olan stratejik ölçüt ve diğer göstergeleri, risk limitlerini ve bu risk limitlerinden sapma oranların tespit etmek. Görüldüğü gibi stratejik ölçüt ve risk limitleri ve sapma oranları belirlenmek suretiyle borç yönetimi sürdürülmektedir.

b) Garanti verilmesi, borç üstlenim taahhüdü sağlanmasl, dış borcun ikrazı ve alacak yönetimine ilişkin strateji, limit, politika ve ilkeleri belirlemek le görevlendirilmiştir.

c) İç ve dış ekonomik koşullarda değişiklik olması halinde gerekli görülürse, (a) ve (b) bentlerinde yer alan stratejik ölçüt ve diğer göstergeler ile risk limitleri ve limitlerden sapma oranlarını değiştirmek

ç) Mücbir sebep hallerinde gerekli görülürse, (a) ve (b) bentlerinde yer alan stratejik ölçüt ve diğer göstergeler ile risk limitleri ve limitlerden sapma oranlarını değiştirmek.

d) (a) bendinde yer alan stratejik ölçüt ve diğer göstergeler ile limit ve limitlerden sapma oranlarının ekonomik gelişmelerle olan tutarlılı̆̆ını aylık olarak gözden geçirmek şeklindedir. Böylelikle ekonomik gelişmelerle uyumlu sapma oranları tespit edilmiş olmaktadır

e) Yapılan borçlanmalar, sağlanan garantiler ve borç üstlenim taahhütleri kapsaminda maruz kalınan risklerin (a) ve (b) bentlerinde yer alan hususlar çerçevesinde üçer aylık dönemler itibariyle değerlendirmesini yapmak. fikrası ile risk yönetiminin mali saydamlık ilkesi çerçevesinde yerine getirilmesi sağlanmış olmaktadır

f) Borç yönetiminden sorumlu birimler arasında gerekli koordinasyonu sağlamak. fikrası ile kararların daha sağlıklı alınmasını ve uygulanmasını kolaylaştırmıştır.

g) Borç portföyünün yapısının değiştirilmesi için yapılması önerilen işlemleri değerlendirmek ve borç yönetiminden sorumlu birimleri talimatlandirmak.

g) Her yll ilgili mali yılın Bütçe Kanununda yer alacak garantili imkân ve dış borcun ikrazı limiti ile borç üstlenim taahhüt limitini teklif etmek hükmü ile belirlenen üst limitler çerçevesinde garanti, ikraz ve borç üstlenimlerinin gerçekleşmesi sağlanmıştır.

h) Kanunun 12 nci maddesinin birinci fikrası uyarınca borç ve risk yönetimi altyapısının geliştirilmesi kapsamında gereken tedbirleri almak ve ilgili birimlerce uygulanmasını sağlama şeklindedir.

Yukarıda sıralanan hükümler çerçevesinde yönetmeliğin 6. Maddesinde borç ve risk yönetimi işlemleri sıralanmıştır.

"Bakanlık Kamu Finansmanı Genel Müdürlüğü bünyesindeki risk yönetiminden sorumlu Genel Müdür Yardımcılığı tarafindan kamu borç, nakit ve risk yönetiminde etkili ve performansa dayalı karar alma süreçlerinin işlemesi için Komiteye bilgi sağlamakta ve önerilerde bulunmakla görevlendirilmiştir. Bu amaçla aşağıdaki işlemler yürütülmektedir.” 
a) Borçlanma, garanti verilmesi ve borç üstlenim taahhüdü sağlanması suretiyle ortaya çıkan doğrudan ve koşullu yükümlülükler ile ...Hazine alacă̆ yaratan işlemlerde izlenecek strateji, politika ve ilkeleri ilgili Bakanlık birimleriyle koordinasyon içinde belirleyerek Komiteye önermek.

b) ...Stratejik ölçütler ve diğer göstergeler ile limitlerini ve limitlerden sapma oranlarını Komiteye önermek

c) Maliyet ve risk göstergelerini belirlemek.

ç) Kamu borç portföyü, bütçe dışı yükümlülükler ile Hazine alacaklarının kisa ve orta vadeli maliyet ve risk analizlerini yapmak.

d) Orta ve uzun vadeli makroekonomik hedefler ile para ve maliye politikaları ile uyumlu borçlanma politikalarının sürdürülebilirlik ve tutarlılık analizlerini yapmak.

e) Yıllık ve üçer aylık borçlanma programını takip etmek.

f) Yapılan borçlanmalar ile bu kapsamda maruz kalınan risklerin... programlarla uyumlu olup olmadığını aylık olarak irdelemek, raporlamak ve önerilerde bulunmak.

g) Birincil ve ikincil piyasaların işleyişini izlemek, değerlendirmek ve borç yönetiminden sorumlu birimlere söz konusu piyasaların geliştirilmesine yönelik önerilerde bulunmak.

g) ...Her yıl bütçe kanunlar ile belirlenecek garantili imkan ve dış borcun ikrazı limiti ile borç üstlenim taahhüt limitine ilişkin teklifleri borç yönetiminden sorumlu birimlerle koordinasyon içinde gerekli analizleri yaparak Komiteye sunmak.

h) ...Borç ve risk yönetimi altyapısının geliştirilmesi kapsamında Komiteye önerilerde bulunmak.

1) ....Borç yönetiminden sorumlu birimlerle koordinasyon içinde risk hesabına yılı bütçesi için teklif edilecek ödeneği hesaplamak.

i) Risk yönetimi kapsamında bilgi sistemlerinin güvenilirliğini değerlendirmek.

j) Borç yönetiminde izlenecek olan politikalara, yapılacak borçlanmanın döviz, faiz ve vade kompozisyonu ile borçlanmada kullanılacak enstrümanların genel özelliklerine ilişkin Komiteye önerilerde bulunmak."

k) Kamu borçportföyünün Komite tarafindan belirlenen risk limitlerinden önemli ölçüde sapmaya yol açacak doğrudan veya koşullu yeni yükümlülük doğuran işlemlerin belirlenen risk ölçütlerine uygunluğu konusunda görüş vermek.

1) Borçlanmadan sorumlu birimler ile koordinasyon içinde yatırımcılarla iletişim, kamu menkul kıymetlerinin ihraç stratejileri ve borçlanma araçlarının geliştirilmesi konularında Komiteye önerilerde bulunmak."

m) Piyasa temsilcileri, yatırımcllar, kreditörler, kredi değerleme kuruluşları ve diğer uluslararası kuruluşlarla ilişkilerin risk kontrol stratejisi çerçevesinde yürütülmesini teminen Komiteye önerilerde bulunmak." 
n) Borç yönetiminden sorumlu birimlerce geliştirilen yeni borçlanma enstrümanlarını risk yönetim stratejileri çerçevesinde değerlendirerek Komiteye önerilerde bulunmak." şeklidedir.

Türkiye'de borçlanma sebebiyle ortaya çıkan maliyet ve ileride karşılaşılması muhtemel olan faiz riski arasındaki alternatif maliyeti belirleyen, bir analiz olarak tanımlanabilen "Risk Altındaki Maliyet Analizi" olarak bilinen analiz yöntemi ağırlıklı olarak kullanılmaktadır (Ateş, 2002: 18).Görüldüğü gibi risk yönetim ve risk ölçüm teknikleri aktif bir şekilde kullanılmaya başlanmıştır. Bu çerçevede borç ofisi uygulamasına geçilmiş ve ofis bünyesinde yer alan orta ofis risk yönetiminden sorumlu tutulmuştur. Aşağıda yer alan Tablo 2'de Türkiye'deki borç ofisi uygulaması ve sorumluluk alanı yer almaktadir.

Tablo-2: Türkiye'de Borç Ofisi Uygulaması

\begin{tabular}{|l|l|}
\hline ÖN OFİS & - Yurtiçi tahvil ihraçları \\
& - Yurtdsşı tahvil ihraçları \\
& - Nakit Yönetimi \\
& - Garanti verilmesi \\
& - İkraz verilmesi \\
\hline ORTA OFIS & - Strateji ve politika alternatifleri geliştirilmesi \\
& - Maliyet ve risk ölçütlerinin belirlenmesi \\
& - Risk analizleri yapılması \\
& - Yıllık ve üçer aylık borçlanma programları \\
& - Risk kontrol, \\
& - Kamu Borç Yönetim Raporunun hazırlanması \\
\hline ARKA OFIS & - İç ve diş borç izlenmesi ve geri ödenmesi \\
& - Raporlama ve \\
& - Bilgi sistemleri yönetimi \\
\hline
\end{tabular}

Kaynak: Ferhat Emil, Maliye Hesap Uzmanları Vakfı Tarafından Düzenlenen "Kamu Borç Yönetimi” Paneli Sunusu, www.treasury.gov.tr/duyuru/basin/Ferhat_sunum_20030530.pdf, Erişim:29.06.2004.

\section{SONUC}

Devletlerin rol ve sorumlulukları her geçen gün artarken gelir kaynaklarının ve çeşitliliğinin aynı hızda artmaması kamu kesimi finansman açıklarının en önemli nedenlerinden birisini oluşturmaktadır. Kamu kesimi finansman açıkları kamu kesimi borçlanma gereksinimini doğurmakta ve borç miktarı her geçen gün artmaktadır. Doğru yönetilen bir borç yönetimi ekonomik ve mali hedeflere ulaşmanın bir aracı haline gelebilmektedir.

Günümüzde dişa açık ekonomilerde ekonomi yönetiminde yer alan aktörler, iç ve diş dinamikleri dikkate alarak uygulayacakları politikalara karar vermektedir. $\mathrm{Bu}$ nedenlerle mali ve ekonomik yapıyı yönetmek çok daha güçleşmekte ve daha karmaşık bir hal almaktadır. Borç yönetimi de bu gelişmelerden doğal olarak etkilenmektedir.

Devletler borçlanma kompozisyonuna karar verirken pek çok değişkeni dikkate alarak karar vermek zorundadır. Hangi piyasadan, hangi vadeyle, hangi menfaatler sağlanacak soruları borç yönetiminin ilk etapta cevaplaması gereken sorular içerisinde yer almaktadır. Ama sadece borç almak ve bunları doğru şekilde kaydetmek ideal bir borç yönetimi için yeterli olmamaktadır. Önemli olan minimum maliyetle gerçekleştirilen bir optimal borç bileşimidir. 
Optimal borç bileşimi gelişmekte olan ülkeler için çok daha önemli hale gelmektedir. Çünkü bu ülkeler gelişmiş ülkelere göre çok daha fazla borçlanmaktadır. Kaynak ihtiyacını karşılayabilmek amacı ile borçlanmaya gidilirken eğer borç yönetiminde etkinlik sağlanamıyorsa borçlanmanın kendisi bir süre sonra borçlanma sebebi olmaktadır. İdeal bir borç yönetiminin maliyetleri azaltan, karşlaşabilecek riskleri önceden tahmin edebilen ve bu risklere karşı gerekli yasal ve kurumsal önlemlere sahip olması gerekmektedir. Çünkü globalleşme sürecine bağlı olarak ortaya çıkan yakın ekonomik ilişkiler ülkeleri dış alemde oluşan risklere de açık hale getirmektedir. Ülkelerin bu riskleri görmezlikten gelerek hareket etmeleri bir süre sonra çok daha ciddi sorunlarla karşılaşılmasına neden olmaktadır. Bu sebeplerle risk yönetimi borç yönetiminin ayrılmaz bir parçası olmaktadır. Borç yönetimi, borç portföyünü yönetirken genel olarak, piyasa riski, borç çevirme riski, likidite riski, kredi riski, uzlaşma riski ve operasyonel risk ile karşı karşıya bulunmakta ve bu riskleri ortadan kaldırabilmek için öncelikle özel kesim tarafindan kullanılan risk ölçüm tekniklerini kullanmaktadır. Günümüzde risk yönetimi borç yönetiminin en önemli ayaklarından birisini oluşturmaktadır. Devletler bu çerçevede yeni borçlanma stratejileri geliştirmekte ve borçlanmayı minimum risk ve maliyetle karşılamaya çalışmaktadır.

Uzun yıllar mali disiplinsizlik sorunu ve bunların sonucunda yaşanan kronik borçlanma sorununu ortadan kaldırmak ve kamu mali dengesini yeniden tesis etmek isteyen Türkiye yapısal reform paketlerini hayata geçirmiş, yasal ve kurumsal düzenlemeler gerçekleştirmiştir. Bu düzenlemelerin başında Kamu Mali Yönetimi ve Kontrol Kanunu ve Kamu Finansmanı ve Borç Yönetiminin Düzenlenmesi Hakkında Kanun gelmektedir. Bu kanunların uygulanmasını kolaylaştıracak tebliğ ve yönetmelikler ve borç yönetimini destekleyecek kurumsal önlemler borç yönetiminde yeni bir dönemin başlamasına neden olmuştur. $\mathrm{Bu}$ yenilikler içerinde en önemlilerinden birisi borç ofisi uygulamasıdır. Borç sözleşmelerinden sorumlu olan ön ofis, risk yönetiminden sorumlu orta ofis ve borçlanma kayıtlarını tutan arka ofis borç yönetimine yeni bir nefes katmıştır. Günümüzde borç yönetimi maliyet minimizasyonunu sağlamaya çalışan, risk yönetim tekniklerini kullanan, daha şeffaf, borçlanma araçlarında çeşitliliği sağlayan bir yapı ile faaliyetlerine devam etmektedir. Ancak yapılan tüm yasal düzenlemeler ve idarenin yeniden yapılandırılması dinamik bir süreç olan borç yönetimi için yeterli değildir. Mevcut mali ve ekonomik koşullara göre gözden geçirmeler ve düzenlemeler yapılarak olası eksiklikler giderilmelidir. Böylelikle hem borçlanmanın doğurduğu olumsuz sonuçlar bertaraf edilebilecek hem de borçlanma daha etkin bir politika aracı haline gelebilecektir..

\section{KAYNAKÇA}

Akar Sevda.(2010) Borç Yönetim Ofisleri Ve Türkiye'de Uygulanabilirliği, Mevzuat Dergisi, Y11:13, Say1:148., https://www.mevzuatdergisi.com/2010/04a/05.htm, Erişim: 10.12.2019

Ateş, Gürkan.(2002), Borç Yönetimi Ofisi ve Türkiye Uygulaması Üzerine Bir Çalışma, Hazine Müsteşarlığı. 
Bal, Harun.(2001).Uluslararası Finansman Dış Borç Yönetimi ve Türkiye, Türkiye Bankalar Birliği Yayın No: 222, İstanbul.

Beşe, Evrim,(2007). Finansal Sistem Stres Testi Uygulamaları ve Türkiye Örneği, Uzmanlık Yeterlilik Tezi, Türkiye Cumhuriyet Merkez Bankası, Ankara.

Borç ve Risk Yönetiminin Koordinasyonu ve Yürütülmesine İlişkin Esas ve Usuller Hakkında Yönetmelik

Cassard Marcel and Landau, David Folkters.(1997). Risk Management of Sovereign Assets and Liabilities, IMF Working Paper, WP No: /97/166.

Ceylan, Ali. (2004). "Finans Bilimi Nereye Gidiyor?”, Erişim: 11.04.2004, www.finansbilimplatformu.com/fyorum/fyorum1201.htm.

Dedeoğlu, Emin. (1995). “Devlet Borç Yönetimi”, İşletme ve Finans, Sayı:111, s.25.

Erçel, Gazi. (1999).“Finansal Risk Yönetimi”, 6. Yıllık Global Finance Conference, Bilgi Üniversitesi, İstanbul, www.tcmb.gov.tr/yeni/evds/konusma/tur/1999/riskyon.html

Fox, Christopher.(2017), A comparison of Active and Passive Portfolio Management, University of Tennessee, University of Tennessee Honors Program, University of Tennessee Research and Creative Exchange.

Hawkins, John and Turner, Philip.(2000) Managing Foreign Debt and Liquidity Risks in Emerging Economies: An Overview, BIS Policy Paper.

Hazine Müsteşarlığı.(2004),Şubat 2004 Kamu Borç Yönetimi Raporu.

Hazine Müsteşarlığı.(2008), Kamu Borç Yönetimi Raporu.

Hazine Müsteşarlığı.(2009),Kamu Borç Yönetimi Raporu.

Jensen, Fred.(2003). Guidelines For Public Debt Management", Proceedings of The Third InterRegional Debt Manegement Conference, Geneva, 3-6 December 2001, United Nations, Newyork and Geneva, UNCTAD/GDS/DMFAS/3.

Kamu Finansmanı ve Borç Yönetiminin Düzenlenmesi Hakkında Kanun

Kappagoda, Nihal. (2004) Best Practices and Key Analytical Functions for Public Debt Management, UNITAR Best Practices Series No:6.

Karacan, Ali İhsan.(1997), "Risk Yönetimi”, Finans Ekonomi ve Politika, içinde, Creative Yayıncılik,

Magnusson, Tomas.(1999) Legal Arrangements For A Debt Office, The Swedish National Debt Office.

Oracle White Paper.(2008) Asset Liability Management: An Overview, An, Oracle Financial Services, http://www.oracle.com/us/industries/financial-services/045581.pdf, Erişim : 11.12.2019.

Paul Mylonas, Schich, Sebastian, Thorgeirsson, Thorsteinn And Wehinger, Gert.(2000) New Issues In Public Debt Management: Government Surpluses In Several OECD Countries, The Common Currency In Europe And Rapidly Rising Debt In Japan, OECD, Economics Department Working Papers No: 239, ECO/WKP(2000)12.

Pehlivan, Nilgün.(2003). "Risk Analizine Dayalı Kamu Borç Yönetimi”, 18.Türkiye Maliye Sempozyumu, Türkiye'de Kamu Borçlanması (Ekonomik ve Sosyal Etkileri Beklentiler), 12-16 Mayıs 2003, Girne, Kuzey Kıbrıs Türk Cumhuriyeti, Marmara Üniversitesi İktisadi ve İdari Bilimler Fakültesi, Maliye Bölümü ve Maliye Araştırma Uygulama Merkezi Yayın No:16.

Piga Gustova.(2001). Derivatives and Public Debt Management, Published in cooperation with the Council on Foreign Relations, International Securities Market, Association (ISMA), Zurich.

Storkey, Ian. (2001). “Sovereign Debt Management: A Risk Management Focus”, The Finance and Treasury Professional.

Structural Risk Management, Policy, Section 7200, Reference Manual, Spring 2005, www.dico.com, Erişim: 10.12.2019.

Türker, Hülya.(2009) Riske Maruz Değer (Value At Risk) Ve Stres Testi: Global Finansal Kriz Sonras1 Etkinliklerinin Değerlendirilmesi, Araştırma Raporu, https://www.spk.gov.tr/SiteApps/Yayin/YayinGoster/1014, Erişim:10.12.2019 
Uçkun, Nurullah ve Kandemir Serkan(2008), Risk Ölçümünde Riske Maruz Değer Metodolojisi ve İMKB'de Bir Uygulama, Muhasebe Finansman Dergisi, Sayı:38.

Uğurlu, Murat, Erdaş, Mehmet, Levent, Eroğlu, Abdullah,(2016), Portföy Yönetiminde Sistematik Olmayan Riski Azaltacak Bir Doğrusal Programlama Model Önerisi, Çankırı Karatekin Üniversitesi İktisadi ve İdari Bilimler Fakültesi Dergisi, Cilt 6, Say1 1.

Uysal, Özge.(1999). Piyasa Riskinin Tespitinde Kullanılan Riskteki Değer (Value At Risk) Yöntemi, Sermaye Piyasası Kurulu Aracılık Faaliyetleri Dairesi, Yeterlik Etüdü, Ankara.

Üzer, Hüseyin Emre.(2002), Risk Yönetiminde Kullanılan Stres Testi Yöntemi, Sermaye Piyasası Kurulu Kurumsal Yatırımcılar Dairesi, Yeterlilik Etüdü Ankara.

Velandia, Antonio.(2004). A Risk Quantification Model for Public Debt Management, Erişim:14.06.2004,http://www.worldbank.org/pdm/pdf/velandia_risk_model.pdf.

World Bank.(2001) Macroeconomic and Financial Management Institute of Eastern and Southern Africa The World Bank Public Debt Management, Public Debt Management, Cash Management and Domestic Debt Market Development Tanzania.

Yaşa, Memduh.(1981) Devlet Borçları, Üçüncü Baskı, İstanbul.

Yıldırım Hakan ve Çolaklayan Arin.(2014) Finansal Yatırım Araçlarında Riske Maruz Değer Uygulamas1, Dokuz Eylül Üniversitesi İktisadi ve İdari Bilimler Fakültesi Dergisi, Cilt:29, Say1:1.

\section{SUMMARY}

As a result of the changes in the understanding of the state, the roles and responsibilities of the state are continuously increasing in almost every state. Therefore, the financing requirement of the state is also growing automatically. States meet this financing deficit through borrowing. As borrowing increases, debt management becomes more important.

Establishing a debt agreement, deciding on the maturity of the debt, the market from which it will be borrowed, keeping the debt records in a proper way are the elements of traditional debt management and it is undoubtedly important. However, in order to intervene in economy, it is more important to use borrowing as a tool.

The success of debt management used for financial and economic purpose is complemented bu the success of other policy instruments. Successful debt management includes risk management. Possible risks increase as much as the globalization process increases. For example, with the globalization process, exchange rates, interest rates, securities and asset prices have become more volatile. In parallel with the increase in volatility, market risk, credit risk, liquidity risk, exchange rate risk, interest rate risk and country risk also increased. In this process, financial products such as swaps, futures, forward, non-coupon and floating rate bonds and asset-backed securities transactions, etc., have emerged. As borrowing volume and diversity increased, identifying, measuring, monitoring and controlling risk has become more important.

When managing debt portfolio, debt management generally faces with several risks included market risk, rollover risk, liquidity risk, credit risk, settlement risk and operational risk. For developing economies, market risk and debt rollover risk are of greater importance. Market risk measured by using scenario analysis, value at risk, cost at risk, stress test. and average time to maturity analysis. In fact, risk measurement techniques can be expressed as "Liability Portfolio" and "Asset-Liability Management Approach". However, risk 
management should be carried out with a very important level of technical knowledge, infrastructure, implementation of the decisions and control of the results of the decisions. For these reasons mentioned above, risk management is much more difficult for developing countries.

A proper risk management must be supported by legislation. Risk management should be carefully monitored and evaluated. Public debt management should be conducted at a transparent, minimum cost and reasonable level of risk. In order to achieve that target, debt management turnes to the benchmark application determined based on cost and risk calculations.

Turkey as a country has been facing with issues such as fiscal indiscipline problem and the chronic debt problems as a result of fiscal indiscipline implemented numerous structural reform packages in order to restore the fiscal balance. Within this framework, many legislative arrangements have been made over years. The Law on Public Financial Management and Control and the Regulation on Public Finance and Debt Management are the most important of these arrangements. These legal arrangements were supported by institutional regulations. Debt management has gained a modern structure by the help of new arrangements related to fiscal system. It may be said that one of the most important of these innovations is the debt office application. In particular, the middle office as a part of debt office is responsible for risk management makes significant contributions to debt management.

Debt management is carried out by determining strategic criteria and other indicators, risk limits and deviation rates from debt, cash and risk management. Now, according to the provisions of law and regulation, debt management is ensured by providing the necessary coordination between the units responsible for debt management. This makes borrowing an active policy tool. 